\title{
Generalized anxiety disorder and resilience during the COVID-19 pandemic: evidence from China during the early rapid outbreak
}

Hao Chen, Junling Gao, Junming Dai, Yimeng Mao, Yi Wang, Suhong Chen, Qianyi Xiao, Yingnan Jia, Pinpin Zheng ${ }^{\dagger}$ and $\mathrm{Hua} \mathrm{Fu}^{* \dagger}$ (D)

\begin{abstract}
Background: Generalized Anxiety Disorder (GAD) is a common but urgent mental health problem during disease outbreaks. Resilience buffers against the negative impacts of life stressors on common internalizing psychopathology such as GAD. This study assesses the prevalence of GAD and examines the protective or compensatory effect of resilience against worry factors during the COVID-19 outbreak.

Methods: A cross-sectional online survey was conducted among Chinese citizens aged $\geq 18$ years from January 31 to February 2, 2020. A total of 4827 participants across 31 provinces and autonomous regions of the mainland of China participated in this study. The Generalized Anxiety Disorder scale (GAD-7), the Connor-Davidson Resilience Scale (CD-RISC), and a self-designed worry questionnaire were used to asses anxiety disorder prevalence, resilience level, and anxiety risk factors. Multivariable logistic regression was used to identify the associations of resilience and worry factors with GAD prevalence after controlling for other covariates.

Results: The prevalence of anxiety disorder was $22.6 \%$ across the 31 areas, and the highest prevalence was $35.4 \%$ in Hubei province. After controlling for covariates, the results suggested a higher GAD prevalence among participants who were worried about themselves or family members being infected with COVID-19 (adjusted odds ratio, AOR 3.40,95\% Cl 2.43-4.75), worried about difficulty obtaining masks (AOR 1.92, 95\%Cl 1.47-2.50), worried about difficulty of distinguishing true information (AOR 1.65,95\%Cl 1.36-2.02), worried about the prognosis of COVID-19 (AOR 2.41, 95\%Cl 1.75-3.33), worried about delays in working (AOR 1.71, 95\%Cl 1.27-.31), or worried about decreased income (AOR 1.45,95\%Cl 1.14-1.85) compared with those without such worries. Additionally, those with a higher resilience level had a lower prevalence of GAD (AOR $0.59,95 \% \mathrm{Cl} 0.51-0.70$ ). Resilience also showed a mediating effect, with a negative influence on worry factors and thereby a negative association with GAD prevalence.
\end{abstract}

Conclusion: It may be beneficial to promote public mental health during the COVID-19 outbreak through enhancing resilience, which may buffer against adverse psychological effects from worry factors.

Keywords: COVID-19 pandemic, Generalized anxiety disorder, Worry factor, Resilience

\footnotetext{
* Correspondence: hfu@fudan.edu.cn

${ }^{\dagger}$ Pinpin Zheng and Hua Fu contributed equally to this work.

Preventive Medicine and Health Education Department, School of Public Health, Fudan University, No.138 Yixueyuan Road, Shanghai 200032, P.R. China
}

(c) The Author(s). 2021 Open Access This article is licensed under a Creative Commons Attribution 4.0 International License, which permits use, sharing, adaptation, distribution and reproduction in any medium or format, as long as you give appropriate credit to the original author(s) and the source, provide a link to the Creative Commons licence, and indicate if changes were made. The images or other third party material in this article are included in the article's Creative Commons licence, unless indicated otherwise in a credit line to the material. If material is not included in the article's Creative Commons licence and your intended use is not permitted by statutory regulation or exceeds the permitted use, you will need to obtain permission directly from the copyright holder. To view a copy of this licence, visit http://creativecommons.org/licenses/by/4.0/ The Creative Commons Public Domain Dedication waiver (http://creativecommons.org/publicdomain/zero/1.0/) applies to the data made available in this article, unless otherwise stated in a credit line to the data. 


\section{Background}

The 2019 coronavirus outbreak (COVID-19) was reported in late December 2019 in Wuhan, China, then spread to the majority of the world in just 2 months and was reclassified as a pandemic on March 11 by World Health Organization (WHO) [1-3]. Official Chinese statistical records stated that by August 4, 2020, a total of 84,465 people had been infected, of which 4644 had died. By the same date, 17,918,582 people have been infected with COVID-19globally, and 686,703 COVID-19related deaths were confirmed across 193 nations [4]. Several countries continue to observe a similar outbreak to that which was observed in China in February; at that time, the number of COVID-19 infected persons rapidly increased from 24,324 to 40,235 in just 7 days, and cases were recorded in every province of mainland China as well as across 24 countries [5]. China adopted tough measures, including quarantining Wuhan on January 23, enacting travel bans,closing highway, shutting down catering companies, and restricting group dinners [6]. In succession, all 31 provinces or autonomous councils have the highest public emergency responses up to January 29 [7]. Although strong policy and pressure are beneficial to controlling the spread of the virus, travel and work restrictions, as well as worry about the outbreak, could induce anxiety, depressive disorders, and post-traumatic stress disorder, which could pose a greater hazard to some individuals than COVID-19 itself [8].

Even under exposure to panic and potentially traumatic events, not everyone develops anxiety [9]. This heterogeneity in response to stress or stimuli was found to be partially owed to the protective psychological capacity of resilience, which can help people avoid psychopathology or maintain favorable mental status in the aftermath of trauma [10]. Resilience not only protects individuals from risk factors but also helps them recover or bounce back from an altered environment following an adversity [11]. The mechanisms of the promotion of mental health by resilience are recognized as facilitating intrapersonal competence (i.e., perceived competence, coping skills, and self-efficacy) and utilizing external resources appropriately (i.e., seeking friends or public agencies for help) [12]. Resilience buffers against the negative impacts of life stressors on common internalizing psychopathology such as generalized anxiety disorder (GAD) symptoms [13, 14]. During the coronavirus pandemic, GAD is unavoidable. About 41 and $23.1 \%$ of the general population of Cyprus reported symptoms associated with mild and moderate-to-severe GAD [15]. Among 1311 community-dwelling individuals in Bangladesh, $37.3 \%$ showed GAD symptoms, compared to an estimate $28 \%$ before the outbreak [16]. Risk factors for GAD problems have been described in prior research. Demographic factors predicting generalized anxiety include being female, being older (more than 30 years), having a higher education (above a bachelor's degree), being married, and being a non-governmental employee [16]. Some behaviors like frequent social media exposure, and spending too much time thinking about the outbreak were positively associated with GAD in Chinese community adults $[17,18]$. However, there has been little research on the ability of resilience, as a positive psychological factor, to protect mental health or compensate for adverse factors during a virus pandemic $[19,20]$. Unlike the deficit model, resilience in positive psychology means more than simply the absence of mental disorder, but functions as a reserve or intrinsic capacity that can be drawn on as a buffer against a wide range of future adversities [21, 22]. Psychological intervention with resilience promotion is suitable for public mental health and proved effective to the general population during the COVID-19 pandemic [23]. In this study, we conducted a survey to assess anxiety among a Chinese population and examine the potential risks and protective effect of resilience for GAD in early rapid outbreak periods.

\section{Methods \\ Study design and participants}

From January 31 to February 22,020, we recruited a sample of 5851 participants aged over 18 years through an online survey and a relevant smartphone link pushed to the WeChat 'moment circle' (a function that can share personal photo or public website link in your moment which is visible to friends on platforms like Twitter and Facebook) by the researches or participants who volunteered to pushed this questionnaire link (Wenjuanxing platform, https://www.wjx.cn/app/survey.aspx). We calculated the minimum sample size, which was 4668 participants, using the following formula: $\frac{Z^{2}{ }_{1-\alpha / 2} p(1-p)}{d^{2}}\left(z^{\wedge}\right.$ $2(1-\alpha / 2)=1.96$; the latest prevalence of GAD (p) was $7.6 \%[24], d=0.1$ ) [25]. All of the participants were required to understand and fill out the questionnaire by themselves through their personal their WeChat account. The survey used convenience sampling to recruit suitable Chinese residents from 31 provinces and autonomous regions (China consists of a total of 34 provinces and autonomous regions) that volunteered to participate. To maximize participant motivation, respondents were entered into a drawing following completion of the questionnaires; those selected received a small monetary reward (RMB 2-100). All questionnaires took approximately $10 \mathrm{~min}$ to complete, and an item with a required answer was established to avoid the return of invalid questionnaires. After cleaning up invalid questionnaires (including those that were returned 
incomplete and those that were completed in less than $5 \mathrm{~min}$ ), 4827 participants were included in the present study. This study was approved by the Institutional Review Board of Fudan University, School of Public Health (IRB\#2020-01-0800) on January 31 and electronic consent was also given by participants by signing the first page of the survey.

\section{Measurements \\ Generalized anxiety disorder, Spitzer (GAD-7)}

The Generalized Anxiety Disorder scale (GAD-7), developed by Spitzer, et.al, is a self-report measure that quantifies the frequency of seven symptoms (e.g., trouble relaxing, worrying too much about different things) over the past 2 weeks to screen for anxiety disorder [26]. Responders are asked to rate each item on a Likert scale from 0 ("not at all") to 3 ("nearly every day"); the items are summed for an overall score ranging from 0 to 21, with higher scores reflecting more severe GAD symptoms. The Chinese version of the GAD-7 (C-GAD-7) has been demonstrated to have acceptable reliability and validity [27]. The pervious normative study defines degree of anxiety into four categories with three cut-offs: no (0-4), mild (5-9), moderate (10-14), and severe anxiety $(\geq 15)[26,28]$. Considering evidence that some level of anxiety is normal during the COVID-19 pandemic, a scale cut-off of 10 and above to represent GAD is appropriate [29].

\section{Resilience, Connor Davidson (CD-RISC-10)}

The abridged Connor-Davidson Resilience Scale (CDRISC) is a self-administered, 10 item scale that reflects the ability to tolerate and overcome adverse situations such as illness, pressure, and failure (item examples: "Tend to bounce back after illness or hardship" and "Can stay focused under pressure") [30]. Each item is rated on a 5-point Likert scale, ranging from 0 ("not true at all") to 4 ("true nearly all the time"), and a higher total score indicates greater resilience. The reliability coefficient of the Chinese version of the CD-RISC was found to be 0.91 [31]. Due to the lack of a recognized cut-off point, resilience scores are usually categorized into three groups: high resilience (score $\geq 75$ th percentile), medium resilience (score $<75$ th percentile and $>25$ th percentile), and low resilience (score $\leq 25$ th percentile) [32].

\section{Worry factors to COVID-19}

Our self-designed worry questionnaire consisted of six items following the question, "Have you been bothered or worried by the following recently?" Respondents were asked to rate each question on a Likert scale from 1 ("not worried at all") to 5 ("very worried"). The questions were categorized into three dimensions and selected from prior research: 1) perception of susceptibility to
COVID-19 (1 question), i.e., worry about COVID-19 infection in oneself or family members [33]; 2) perceived barriers to preventing COVID-19 (2 questions), i.e., worry about difficulty obtaining safety equipment such as medical masks or worry about difficulty distinguishing authentic [34] and valid information about the COVID19 pandemic across various social media platforms [35]; 3) perceived hazard of COVID-19 (3 questions), i.e., worry about the prognosis of COVID-19 [36], delays in working, or decreased income [37]. In the present study, the Cronbach's alpha coefficient for the internal consistency (reliability) of worry factors to COVID-19 was 0.81 and two subscale were 0.77 (perceived barriers to preventing COVID-19) and 0.63 (perceived hazard of COVID-19). However, perception of susceptibility to COVID-19 was not suitable to calculate individual reliability for only containing one item. The sampling adequacy for the 6-item scale was excellent (Kaiser-MeyerOlkin $=0.91$ ). Inter-item correlations were sufficiently large for principal components analysis (PCA) (Bartlett's test of sphericity: $\left.\chi^{2}(21)=8299.1, p<0.001\right)$. The PCA revealed three factors, which in combination explained $72.10 \%$ of the variance. An examination of the factor loadings after rotation suggested as expected that factor 1 (perceived hazard of COVID-19) had three items (loading factors, namely, worried about prognosis (0.67), working delay (0.79), and decreased income (0.81); factor 2 included 2 items, difficulty obtaining safety equipment (0.79) and distinguishing authentic health information (0.78); factor 3 only contained 1item, worried about susceptibility to COVID-19 (0.86). The three factors accounted for $33.83,22.16$, and $16.11 \%$ of the explained variance, respectively.

\section{Covariates}

Covariates in this study included sex, age, educational level [junior college (education for 16-18 year old and not award academic degree) and above (junior college, bachelor (education for $>18$ year old), master and doctor), under junior college (junior high school, senior high school)], marital status [married, unmarried and other (including divorced and widowed)], areas (Hubei province, cities with COVID-19 $\leq 100$, and cities with COVID-19 > 100), location (city, town and village), and community COVID-19 pandemic status, measured by questions such a "Are there COVID-19 patients, medical observations or suspected patients in your living community/neighborhood?" (no COVID-19 cases, under medical observation, suspected cases, confirmed cases, unknown,) and ones regarding exposure to Hubei within the past month (yes, no,) and whether the participants had medical workers or people with a medical education background in their family (yes, no). 


\section{Statistical analysis}

The demographic characteristics and exposure history of the study sample are presented as means with $S D$ s or percentages by different levels of COVID-19 outbreak. Based on the COVID-19 outbreak level of every province (latest data from February 1, 0:00 to 24:00) [38], we divided these 31 areas into three subgroups-Hubei, with $>$ 10,000 COVID-19 patients, 16 provinces or auto regions with $\geq 100 \& \leq 10,000$ COVID-19 patients, and 14 provinces or autonomous regions with $<100$ COVID-19 patients. The $\chi^{2}$ test was used to examine the distribution differences in GAD prevalence, anxiety worry factors, and resilience among the above three areas. Multivariable logistic regression analyses were used to explain the associations among the prevalence of GAD, worry factors, and resilience after controlling for covariates. We considered two-sided $p$-values of less than 0.05 statistically significant. All of the analyses were performed using SPSS version 22.0 (SPSS, Chicago, IL, USA). Structural equation modeling was used to assess the standardized coefficients (SSCs) among resilience, GAD, and anxiety risk factors. Amos 22.0 (SPSS, Chicago, IL, USA) was used to determine whether the data fit the model.

\section{Results}

\section{Demographic characteristics and exposure history of} participants

Our analysis including 4827 participants dispersed across 31 provinces and autonomous regions in mainland of China. They were aged between 18 and 85 (mean, 32.32; SD, 9.98); 67.7\% of them were female, and $62.5 \%$ were urban residents. $78.5 \%$ participants had received bachelor or master education. $36.7 \%$ of participants were still working and $20.8 \%$ were students. $54.0 \%$ of them were married. $76.8 \%$ participants reported nonconfirmed or related cases exposure in their living community, while $8.4 \%$ participants reported under medical observation cases exposure, suspected cases (5.4\%), confirmed cases $(9.4 \%)$ in their living neighborhood. Only 4.9\% participants living in Hubei and $7.9 \%$ had travelled to Hubei since November, 2019.

\section{GAD prevalence and distribution of worry factors to COVID-19}

According to cut-off points, $32.7 \%$ of respondents had mild GAD (score: 5-9), 13.0\% had moderate GAD (score: 10-14), and 9.6\% had severe GAD (score: $\geq 15$ ). In the present study, we selected a GAD scale cut-off point of 10 and found that the prevalence of GAD was $22.6 \%$ among the respondents. Of participants, $37.5 \%$ reported medical education background in their immediate family, while $78.9 \%$ of participants reported worry about the outbreaks regarding susceptibility to COVID-
19, difficulty obtaining masks (72.6\%), difficulty distinguishing valid information (75.0\%), decreased income (79.4\%), delays in working, and worry about the prognosis of COVID-19 (85.9\%). As shown in Table 1, univariate analysis indicated that GAD prevalence, worry about susceptibility to COVID-19, worry about barriers to preventing COVID-19, and worry about the hazards of COVID-19 were higher in Hubei than in the other affected areas $(P<0.05)$.

\section{Worry factors to COVID-19, resilience, and GAD prevalence}

The crude associations among sources of anxiety disorder, resilience, and GAD prevalence are shown in Model 1, Table 2. The medium and high resilience groups were combined into a high resilience group due to the lack of statistical difference between the two groups $(P>0.05)$. Those with a higher resilience level had a decreased GAD prevalence (OR 0.65, 95\%CI $0.56-$ 0.76). Our findings also showed a higher GAD prevalence among participants who worried about themselves or family members being infected with COVID-19 (OR 3.12 , 95\%CI 2.25-4.34), difficulty obtaining masks (OR $1.75,95 \% \mathrm{CI} 1.35-2.26)$, difficulty distinguishing information (OR 1.83, 95\%CI 1.51-2.22), the prognosis of COVID-19 (OR 2.37, 95\%CI 1.72-3.26), delays in working (OR 1.70, 95\%CI 1.27-2.27), or decrease income (OR 1.62, 95\%CI 1.28-2.01) compared to those without such worries. Similar results regarding resilience and GAD risk factors were found in Model 2. We also found that participants with higher educational attainment (bachelor degree and above) had lower GAD prevalence (AOR 0.56, 95\%CI 0.47-0.67), while those with exposure to Hubei province in the past month showed an increased GAD prevalence (AOR 1.90, 95\%CI 1.42-2.54).

The SEM of worry factor to COVID-19, resilience, and GAD As shown in Fig. 1, structural equation modeling (SEM) was used to examine the combined underlying psychological mechanism of GAD prevalence. Compared to the criteria of goodness-of-fit statistics, SEM was a better fit to the data $\left(\chi^{2}\right.$ degrees of freedom $[\mathrm{df}]=168.82$; root mean square error of approximation [RMSEA] $=0.04$; goodness of fit index, $[\mathrm{GFI}]=0.99$; comparative fit index $[\mathrm{CFI}]=0.99$ ), and all of the paths were statistically significant $(p<0.05)$. Our findings suggested a mediating effect of resilience, with influenced worry factors in the negative direction $(\mathrm{SSC}=-0.18, p<0.001)$ and was thereby negatively associated with GAD prevalence $(\mathrm{SSC}=-0.13, p<0.001)$. Worry factors were also indirectly positively associated with GAD via resilience $($ SSCs $=-0.18 \times-0.13, p<0.001)$ and directly associated with GAD (SSC $=0.47, p<0.05)$. Meanwhile, high education attainment was negatively correlated with GAD 
Table 1 The detailed distributions of areas with different outbreak levels

\begin{tabular}{|c|c|c|c|c|}
\hline & Total & $\begin{array}{l}\text { COVID-19 }>10,000 \text { in } \\
\text { Hubei province, } n= \\
130\end{array}$ & $\begin{array}{l}\text { COVID- } 19 \geq 100 \& \leq 10,000 \text { in } 16 \\
\text { provinces or autonomous regions, } \\
n=3464\end{array}$ & $\begin{array}{l}\text { COVID- } 19<100 \text { in } 14 \text { provinces } \\
\text { or autonomous regions, } n= \\
1233\end{array}$ \\
\hline $\begin{array}{l}\text { Age (years, mean (standard } \\
\text { deviation)) }\end{array}$ & $\begin{array}{l}32.3 \\
(9.9)\end{array}$ & $29.9(9.2)$ & $32.2(9.9)$ & $32.9(10.1)$ \\
\hline Male & $\begin{array}{l}1560 \\
(32.3 \%)\end{array}$ & $54(41.5 \%)$ & $1104(31.9 \%)$ & $402(32.6 \%)$ \\
\hline \multicolumn{5}{|l|}{ Location } \\
\hline City & $\begin{array}{l}3018 \\
(62.5 \%)\end{array}$ & 71 (54.6\%) & $2152(62.1 \%)$ & 795 (64.5\%) \\
\hline Town & $\begin{array}{l}902 \\
(18.7 \%)\end{array}$ & $28(21.5 \%)$ & $651(18.8 \%)$ & $223(18.1 \%)$ \\
\hline Village & $\begin{array}{l}907 \\
(18.8 \%)\end{array}$ & $31(23.8 \%)$ & $661(19.1 \%)$ & $215(17.4 \%)$ \\
\hline Bachelor degree and above & $\begin{array}{l}3778 \\
(78.5 \%)\end{array}$ & $108(83.0 \%)$ & $2742(79.2 \%)$ & $938(76.1 \%)$ \\
\hline \multicolumn{5}{|l|}{ Community COVID-19 epidemic } \\
\hline Non COVID-19 case & $\begin{array}{l}3194 \\
(66.2 \%)\end{array}$ & 47 (36.2\%) & $2282(65.9 \%)$ & $865(70.2 \%)$ \\
\hline Under medical observation & $\begin{array}{l}404 \\
(8.4 \%)\end{array}$ & $9(6.9 \%)$ & $304(8.8 \%)$ & $91(7.4 \%)$ \\
\hline Suspected case & $\begin{array}{l}262 \\
(5.4 \%)\end{array}$ & $18(13.8 \%)$ & $178(5.1 \%)$ & $66(5.4 \%)$ \\
\hline Confirmed case & $\begin{array}{l}454 \\
(9.4 \%)\end{array}$ & $31(23.8 \%)$ & $302(8.7 \%)$ & $121(9.8 \%)$ \\
\hline Unknown & $\begin{array}{l}513 \\
(10.6 \%)\end{array}$ & $25(19.2 \%)$ & $398(11.5 \%)$ & $90(7.3 \%)$ \\
\hline $\begin{array}{l}\text { Exposure to Hubei during a } \\
\text { month }\end{array}$ & $\begin{array}{l}266 \\
(5.5 \%)\end{array}$ & - & $208(6.0 \%)$ & $58(4.7 \%)$ \\
\hline Medical worker in your family & $\begin{array}{l}1812 \\
(37.5 \%)\end{array}$ & 42 (32.3\%) & $1276(36.8 \%)$ & $494(40.1 \%)$ \\
\hline GAD prevalence & $\begin{array}{l}1090 \\
(22.6 \%)\end{array}$ & $46(35.4 \%)$ & $754(21.8 \%)$ & $290(23.5 \%)$ \\
\hline High resilience & $\begin{array}{l}3582 \\
(74.2 \%)\end{array}$ & $95(73.1 \%)$ & $2572(74.2 \%)$ & 915 (74.2\%) \\
\hline $\begin{array}{l}\text { Worried self and family member } \\
\text { were susceptibility to COVID- } \\
19^{* * *}\end{array}$ & $\begin{array}{l}3810 \\
(78.9 \%)\end{array}$ & $114(87.7 \%)$ & $2739(79.1 \%)$ & 957 (77.6\%) \\
\hline $\begin{array}{l}\text { Worried about difficulty } \\
\text { obtaining masks*** }\end{array}$ & $\begin{array}{l}3672 \\
(76.1 \%)\end{array}$ & 105 (80.8\%) & $2647(76.4 \%)$ & $920(74.6 \%)$ \\
\hline $\begin{array}{l}\text { Worried about difficulty } \\
\text { distinguishing valid } \\
\text { information*** }\end{array}$ & $\begin{array}{l}3503 \\
(72.6 \%)\end{array}$ & 111 (85.4\%) & $2531(73.1 \%)$ & $861(69.8 \%)$ \\
\hline $\begin{array}{l}\text { Worried about decrease } \\
\text { income }\end{array}$ & $\begin{array}{l}3618 \\
(75.0 \%)\end{array}$ & $104(80.0 \%)$ & $2609(75.3 \%)$ & 905 (73.4\%) \\
\hline Worried about delay working ${ }^{* * *}$ & $\begin{array}{l}3833 \\
(79.4 \%)\end{array}$ & $114(87.7 \%)$ & $2766(79.8 \%)$ & $953(77.3 \%)$ \\
\hline $\begin{array}{l}\text { Worried about prognosis of } \\
\text { COVID- } 19\end{array}$ & $\begin{array}{l}4148 \\
(85.9 \%)\end{array}$ & $111(85.4 \%)$ & $2963(85.5 \%)$ & $1074(87.1 \%)$ \\
\hline
\end{tabular}

*** representing $P$ value $<0.001$

(SSC $=-0.11, p<0.001$ ), and exposure to Hubei in the past month was positively associated with GAD (SSCs = $0.09, p<0.05)$.

\section{Discussion}

In this study, $22.6 \%$ of the sample experienced moderate to severe GAD during the early rapid outbreak in China. 
Table 2 Odds ratios for GAD prevalence by demographic characteristic, resilience and worried factors to COVID-19

\begin{tabular}{|c|c|c|c|}
\hline & Cases & Model 1 & Model 2 \\
\hline & & OR $(95 \% \mathrm{Cl})$ & OR $(95 \% \mathrm{Cl})$ \\
\hline \multicolumn{4}{|l|}{ Age (years) } \\
\hline $18-24$ & $152(20.6 \%)$ & & 1 (ref) \\
\hline $25-44$ & $734(25.7 \%)$ & & $1.43(1.14,1.79)$ \\
\hline 45 and above & $204(16.6 \%)$ & & $1.09(0.79,1.49)$ \\
\hline \multicolumn{4}{|l|}{ Sex } \\
\hline Male & $359(23.0 \%)$ & & 1 (ref) \\
\hline Female & $731(22.4 \%)$ & & $0.90(0.77,1.06)$ \\
\hline \multicolumn{4}{|l|}{ Marriage status } \\
\hline Unmarried & $375(17.8 \%)$ & & 1 (ref) \\
\hline Married & $676(25.9 \%)$ & & $1.52(1.24,1.86)$ \\
\hline Divorced or widowed & 37 (33.0\%) & & $2.32(1.44,3.75)$ \\
\hline \multicolumn{4}{|l|}{ Education attainment } \\
\hline Below college & $347(33.4 \%)$ & & 1 (ref) \\
\hline College and above & $743(19.6 \%)$ & & $0.56(0.47,0.67)$ \\
\hline \multicolumn{4}{|l|}{ Location } \\
\hline City & $683(22.6 \%)$ & & 1 (ref) \\
\hline Town & $200(22.2 \%)$ & & $0.82(0.67,1.00)$ \\
\hline Village & $207(22.8 \%)$ & & $0.91(0.74,1.11)$ \\
\hline \multicolumn{4}{|l|}{ Cities with different COVID-19 prevalence } \\
\hline Cities of COVID-19 < 100 & $290(23.5 \%)$ & & 1 (ref) \\
\hline Cities of COVID-19> 100 & $754(21.8 \%)$ & & $0.89(0.76,1.06)$ \\
\hline Hubei (COVID-19 > 10,000) & $46(35.4 \%)$ & & $0.99(0.61,1.63)$ \\
\hline \multicolumn{4}{|l|}{ Exposure to Hubei during a month } \\
\hline No & $715(21.7 \%)$ & & 1 (ref) \\
\hline Yes & $127(33.4 \%)$ & & $1.90(1.42,2.54)$ \\
\hline \multicolumn{4}{|l|}{ Medical worker in your family } \\
\hline No & $715(23.7 \%)$ & & 1 (ref) \\
\hline Yes & $375(20.7 \%)$ & & $0.96(0.82,1.12)$ \\
\hline \multicolumn{4}{|l|}{ Resilience } \\
\hline Lower level (1st quartile) & $398(32.0 \%)$ & 1 (ref) & 1 (ref) \\
\hline Higher level (2nd to 4th quartile) & $692(19.3 \%)$ & $0.65(0.56,0.76)$ & $0.59(0.51,0.70)$ \\
\hline \multicolumn{4}{|l|}{ Worry factors to COVID-19 (ref: not worry) } \\
\hline Worried self and family member were susceptible to COVID-19 & $1042(27.3 \%)$ & $3.12(2.25,4.34)$ & $3.40(2.43,4.75)$ \\
\hline Worried about difficulty obtaining mask & $1002(27.3 \%)$ & $1.75(1.35,2.26)$ & $1.92(1.47,2.50)$ \\
\hline Worried about difficulty distinguishing information & $934(26.7 \%)$ & $1.83(1.51,2.22)$ & $1.65(1.36,2.02)$ \\
\hline Worried about prognosis of COVID-19 & $1043(25.1 \%)$ & $2.37(1.72,3.26)$ & $2.41(1.75,3.33)$ \\
\hline Worried about delay in working & $1017(26.5 \%)$ & $1.70(1.27,2.27)$ & $1.71(1.27,2.31)$ \\
\hline Worried about decreased decrease income & $973(26.9 \%)$ & $1.62(1.28,2.01)$ & $1.45(1.14,1.85)$ \\
\hline
\end{tabular}

$O R$ Odds ratio, $A O R$ Adjusted odds ratio

Hubei province, the first and worst outbreak area with over 10,000 COVID-19 patients, showed the highest GAD prevalence (35.4\%). Participants who had traveled to Hubei within the past month also showed an increased GAD risk (AOR 1.90, 95\%CI 1.42-2.54). This GAD prevalence during the outbreak period was much higher than that found by the latest report in a national sample, which indicated a $7.6 \%$ prevalence of anxiety 


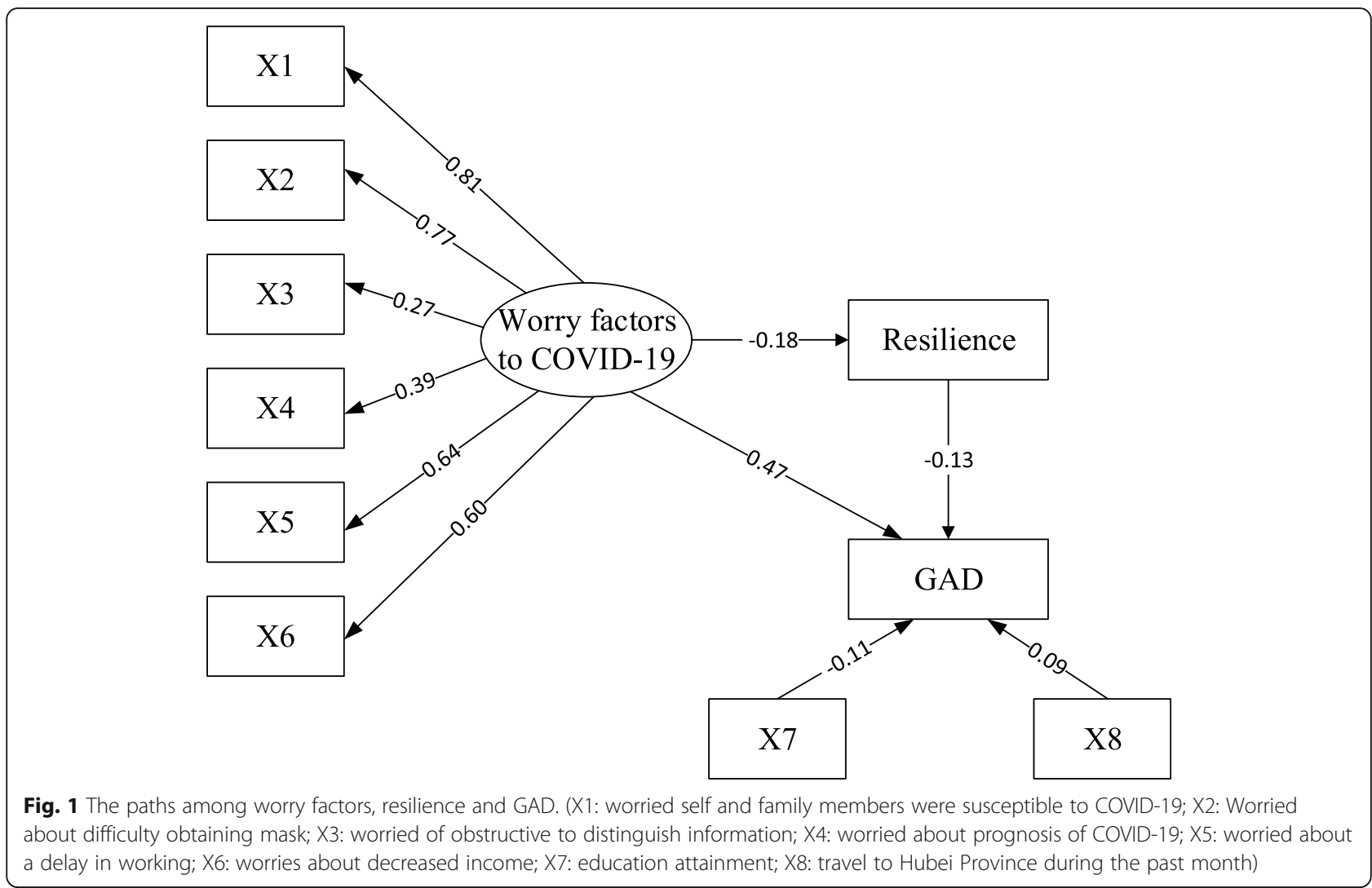

disorders in China [24]. During the SARS [39], MERS [33], and Ebola [24] outbreaks, people were also more vulnerable to mental disorders caused by specific worry factors due to the high possibility of being infected by these viruses, the lack of appropriate prevention measures, and the strict biosecurity restrictions.

Determining the specific worry factors contributing to public anxiety may be beneficial to preventing mental disorders. This study found that worry about oneself or family members being infected with COVID-19 was associated with highest GAD prevalence, which is comparable to results from South Korea regarding fear of infection [33]. During the early stage of an outbreak, wearing a medical mask is one of the prevention measures recommended by WHO to limit the spread of certain respiratory diseases [40]; the initial shortage of these masks caused social panic [34]. Despite rationing of masks to each community to ensure hospitals' demands were met, the hospitals still asked for social donations of protective supplies [34], which may cause higher GAD prevalence associated with obtaining masks in this study. While travel was restricted, people were still exposed to erroneous information on social media like prognosis of COVID-19 patients' sequela or death and that drinking can prevent coronavirus infection, making it difficult for people to distinguish valid information [35], which may increase the GAD prevalence. Although COVID-19 vaccination opened to market for several weeks, the global inequities of vaccine distribution due to only a limited number of countries possess capacity to manufacture vaccines on their own against the virus [41].; thus, people may still be vulnerable to anxiety disorders due to concerns regarding the susceptibility and prognosis of COVID-19. Participants who were worried about delays in working and about decreased income were directly influenced by the uncertain work resumption time, for that stressful income situations can increase common mental health problems like anxiety, depression, etc. [42].

The most important finding of this study was the potential protective factors related to GAD. Resilience, the ability to maintain a state of normal equilibrium in the face of extremely unfavorable circumstances [11], has been demonstrated to have protective effects against mental disorders like depression [43], anxiety [44], and PTSD [45] after trauma exposure, which is consistent with the findings of this study. The capacity to tolerate high levels of fear and still perform efficiently within a military context has been demonstrated to be associated with high resilience [46], further explaining how high resilience is associated with low anxiety (fear of COVID19). Additionally, we found that those with a college education or above had only about half the GAD prevalence of those with a lower education level. Considering 
the difficulties in distinguishing valid and truthful information, which is a source of public anxiety, more educated people can more easily find, distinguish, and accept correct information [47]. Furthermore, high educational attainment enhances one's resilience level, which may indirectly compensate for mental disorders, especially after trauma $[9,48]$. Ahmed performed a review and concluded that two underlying types of positive factors promote resilience: internal characteristics (selfesteem, trust, resourcefulness, secure attachments, sense of humor) and external factors (safety, religious affiliation, strong role models) [49]. Furthermore, this study identified a possible buffering function of resilience that can mediate the unfavorable effect of worry factors on GAD prevalence, which is consistent with previous research [50]. Moreover, the buffering effect of resilience on mental disorders caused by posttraumatic stress has been found to be stronger in individuals with more trauma experience [51]. Resilience is not a stable characteristic but a changeable one. For example, enhancing emotional regulation, cognitive flexibility and reappraisal, positive emotions, meaning-making, having purpose in life, and the ability to harness social support may help reinforce resilient functioning [52]. An assetbased approach through promoting resilience could be a novel approach to promoting public health-building upon the recognized strengths and developing the potential strengths of individuals, communities, and organizations rather than focusing on avoiding individual risk factors [53]. A study conducted at an Ottawa company using an asset mapping method identified 25 assets types that can enhance resilience levels in seven categories: (a) awareness, (b) human resources, (c) information and communication, (d) leadership and culture, (e) operational infrastructure, (f) physical resources, and (g) social capital [54]. An asset-based approach is suitable for addressing different characteristics of communities, regions, and even countries to help enact target policies.

There are some potential limitations to this study. First, causal inferences regarding the effects of worry factors and resilience on GAD prevalence cannot be made from this cross-sectional study. Second, due to the online survey process, selection bias, such as having fewer male respondents, may have affected the results. Lastly, this study did not collect data on mental disorder fluctuations that may characterize early rapid outbreak periods to some extent; the mental disorder prevalence could fluctuate over the course of the COVID-19 pandemic.

\section{Conclusion}

In conclusion, the findings of this study suggest that there is currently a high prevalence of GAD in China, especially in the first and worst outbreak area, Hubei province, and among those who traveled to Hubei in the month prior to data collection. Furthermore, all of the worries except worry about the prognosis of COVID-19 were found to be more prevalent in Hubei Province than in other outbreak areas. Worries about susceptibility to COVID-19 are positively and highly associated with GAD prevalence, and perceived barriers to preventing COVID-19 and perceived hazards of COVID-19 are also positively associated with GAD prevalence to some extent. A high level of resilience and higher education attainment are protective factors against GAD; resilience, in particular, may buffer against the development of mental disorders due to anxiety risk factors. It may be beneficial to decrease public anxiety prevalence through health education to enhance efficacy for accessibility of medical or mask supplies and objective understanding of infectiousness, harmfulness of novel coronavirus. The resilience promotion may be a critical and conducive program for COVID-19 mental health promotion.

\section{Abbreviations}

Cl: Confidence interval; GAD: Generalized Anxiety Disorder scale; OR: Odds ratio; SPSS: Statistical Package for the Social Sciences; USA: United States of America

\section{Acknowledgements}

Not applicable.

\section{Authors' contributions}

$P Z, J G, J D, Y J, Q X$ and HF designed the study and obtained the data, HC undertook the analysis supervised by $\mathrm{PZ}$ and $\mathrm{HF}$ and wrote the manuscript, $\mathrm{JZ}$ and JD organized the survey, and YM, YW, SC and HC performed the survey. All of the authors read the final manuscript and agree with the text.

\section{Funding}

This work was supported by the National key R\&D Program of China (grant number: 2018 YFC2002000 \& 2018YFC2002001) and National Natural Science Foundation of China (grant number 71573048). The funder of HF designed the study and obtained the data.

\section{Availability of data and materials}

The data that support the findings of this study are available from the School of Public Health of Fudan University apply to the availability of these data, which were used under license for the current study, and so are not publicly available. Data are however available from the authors upon reasonable request and with permission of School of Public Health of Fudan University.

\section{Declarations}

Ethics approval and consent to participate Informed consent was obtained from all subjects involved in the study. The questionnaire was electronically distributed and consent was obtained by asking the participants to read a box stating "I have read the information and agree to participate in this study" before they could access to the whole questionnaire. The Institutional Review Board of the Fudan University, School of Public Health (IRB\#2020-01-0800), approved the ethic protocol.

\section{Consent for publication}

Not applicable.

Competing interests

The author declare that they have no competing interest. 
Received: 29 June 2020 Accepted: 28 September 2021

Published online: 09 October 2021

\section{References}

1. World Health Organization. Coronavirus disease 2019 (COVID-19) Situation Report - 51,SURVEILLANCE. Geneva: WHO; 2020. https://www.who.int/docs/ default-source/coronaviruse/situation-reports/20200311-sitrep-51-covid-19. pdf?sfursn=1ba62e57_10.

2. Chen N, Zhou M, Dong X, Qu J, Gong F, Han Y, et al. Epidemiological and clinical characteristics of 99 cases of 2019 novel coronavirus pneumonia in Wuhan, China: a descriptive study. Lancet. 2020;395(10223):507-13. https:// doi.org/10.1016/S0140-6736(20)30211-7.

3. Huang C, Wang Y, Li X, Ren L, Zhao J, Hu Y, et al. Clinical features of patients infected with 2019 novel coronavirus in Wuhan, China. Lancet. 2020;395(10223):497-506.

4. World Health Organization. Coronavirus disease (COVID-2019) situation reports-196,SURVEILLANCE. Geneva: WHO; 2020. https://www.who.int/docs/ default-source/coronaviruse/situation-reports/20200803-covid-19-sitrep-196cleared.pdf.

5. Chinese Government.Update on epidemic situation of novel coronavirusinfected pneumonia in Hubei Province by Feb 10, 2020. Beijing: Gov.cn; 2020. http://www.nhc.gov.cn/xcs/yqfkdt/202002/167a0e01b2d24274 b03b2ca961107929.shtml.

6. Globa Times.Real-time update on coronavirus outbreak. Global Times Published; 2020. https://www.globaltimes.cn/content/1177737.shtml?xn.

7. Chinadaily.com.cn.Tibet activates highest-level public health alert Chinadaily.com.cn, 2020.01.29. https://www.chinadaily.com.cn/a/202001/29/ WS5e318a36a3101282172739c1.html.

8. Shultz JM, Baingana F, Neria Y. The 2014 Ebola outbreak and mental health: current status and recommended response. JAMA. 2015;313(6):567-8. https://doi.org/10.1001/jama.2014.17934.

9. Ssenyonga J, Owens V, Olema DK. Posttraumatic growth, resilience, and posttraumatic stress disorder (PTSD) among refugees. Procedia Soc Behav Sci. 2013;82:144-8. https://doi.org/10.1016/j.sbspro.2013.06.238.

10. Agaibi CE, Wilson JP. Trauma, PTSD, and resilience: a review of the literature Trauma Violence Abus. 2005;6(3):195-216. https://doi.org/10.1177/152483 8005277438

11. Bonanno GA. Loss, trauma, and human resilience: have we underestimated the human capacity to thrive after extremely aversive events? Am Psychol. 2004:59(1):20-8. https://doi.org/10.1037/0003-066X.59.1.20.

12. Wang JL, Zhang DJ, Zimmerman MA. Resilience theory and its implications for Chinese adolescents. Psychol Rep. 2015;117(2):354-75. https://doi.org/1 0.2466/16.17.PR0.117c21z8

13. Sheerin CM, Lind MJ, Brown EA, Gardner CO, Kendler KS, Amstadter AB. The impact of resilience and subsequent stressful life events on MDD and GAD. Depress Anxiety. 2018;35(2):140-7. https://doi.org/10.1002/da.22700.

14. Pechmann C, Petermann F, Brahler E, Decker O, Schmidt S. Does low resilience causes to greater psychological impairment? Psychiatr Prax. 2015; 42(4):197-201. https://doi.org/10.1055/s-0034-1369920.

15. Solomou I, Constantinidou F. Prevalence and Predictors of Anxiety and Depression Symptoms during the COVID-19 Pandemic and Compliance with Precautionary Measures: Age and Sex Matter. Int J Environ Res Public Health. 2020;17(14):4924

16. Islam MS, Ferdous MZ, Potenza MN. Panic and generalized anxiety during the COVID-19 pandemic among Bangladeshi people: An online pilot survey early in the outbreak. J Affect Disord. 2020;276:30-7. https://doi.org/10.1016/ j.jad.2020.06.049.

17. Huang $Y$, Zhao N. Generalized anxiety disorder, depressive symptoms and sleep quality during COVID-19 outbreak in China: a web-based crosssectional survey. Psychiatry Res. 2020;288:112954. https://doi.org/10.1016/j. psychres.2020.112954.

18. Gao J, Zheng P, Jia Y, Chen H, Mao Y, Chen S, et al. Mental health problems and social media exposure during COVID-19 outbreak. PLoS One. 2020;15(4): e0231924. https://doi.org/10.1371/journal.pone.0231924.

19. Choi EPH, Hui BPH, Wan EYF. Depression and Anxiety in Hong Kong during COVID-19. Int J Environ Res Public Health. 2020;17(10). https://doi.org/10.33 90/ijerph17103740.

20. Shevlin M, Nolan E, Owczarek M, McBride O, Murphy J, Gibson Miller J, et al. COVID-19-related anxiety predicts somatic symptoms in the UK population. Br J Health Psychol. 2020;25(4):875-82. https://doi.org/10.1111/bjhp.12430.
21. Davydov DM, Stewart R, Ritchie K, Chaudieu I. Resilience and mental health. Clin Psychol Rev. 2010;30(5):479-95. https://doi.org/10.1016/j.cpr.2010.03.003.

22. Fredrickson BL, Tugade MM, Waugh CE, Larkin GR. What good are positive emotions in crises? A prospective study of resilience and emotions following the terrorist attacks on the United States on September 11th, 2001. J Pers Soc Psychol. 2003;84(2):365-76. https://doi.org/10.1037/0022-3 514.84.2.365.

23. He Z, Chen J, Pan K, Yue Y, Cheung T, Yuan Y, et al. The development of the 'COVID-19 psychological resilience Model' and its efficacy during the COVID-19 pandemic in China. Int J Biol Sci. 2020;16(15):2828-34. https://doi. org/10.7150/ijbs.50127.

24. Ji D, Ji YJ, Duan XZ, Li WG, Sun ZQ, Song XA, et al. Prevalence of psychological symptoms among Ebola survivors and healthcare workers during the 2014-2015 Ebola outbreak in Sierra Leone: a cross-sectional study. Oncotarget. 2017:8(8):12784-91. https://doi.org/10.18632/oncota rget.14498.

25. Charan J, Biswas T. How to calculate sample size for different study designs in medical research? Indian J Psychol Med. 2013;35(2):121-6. https://doi. org/10.4103/0253-7176.116232.

26. Lowe B, Decker O, Muller S, Brahler E, Schellberg D, Herzog W, et al. Validation and standardization of the generalized anxiety disorder screener (GAD-7) in the general population. Med Care. 2008;46(3):266-74. https://doi. org/10.1097/MLR.0b013e318160d093.

27. Tong X, An DM, McGonigal A, Park SP, Zhou D. Validation of the generalized anxiety Disorder-7 (GAD-7) among Chinese people with epilepsy. Epilepsy Res. 2016;120:31-6. https://doi.org/10.1016/j.eplepsyres.2 015.11.019.

28. Hinz A, Klein AM, Brahler E, Glaesmer H, Luck T, Riedel-Heller SG, et al. Psychometric evaluation of the generalized anxiety disorder screener GAD7, based on a large German general population sample. J Affect Disord. 2017;210:338-44. https://doi.org/10.1016/j.jad.2016.12.012.

29. Singh P, Cumberland WG, Ugarte D, Bruckner TA, Young SD. Association between generalized anxiety disorder scores and online activity among US adults during the COVID-19 pandemic: cross-sectional analysis. J Med Internet Res. 2020;22(9):e21490. https://doi.org/10.2196/21490.

30. Campbell-Sills L, Stein MB. Psychometric analysis and refinement of the Connor-Davidson resilience scale (CD-RISC): validation of a 10-item measure of resilience. J Trauma Stress. 2007;20(6):1019-28. https://doi.org/10.1002/ jts.20271.

31. Yu XN, Zhang JX. Factor analysis and psychometric evaluation of the Connor-Davidson resilience scale (CD-RISC) with Chinese people. Soc Behav Personal. 2007;35(1):19-30. https://doi.org/10.2224/sbp.2007.35.1.19.

32. Min JA, Jung YE, Kim DJ, Yim HW, Kim JJ, Kim TS, et al. Characteristics associated with low resilience in patients with depression and/or anxiety disorders. Qual Life Res. 2013;22(2):231-41. https://doi.org/10.1007/s11136012-0153-3

33. Jeong H, Yim HW, Song YJ, Ki M, Min JA, Cho J, et al. Mental health status of people isolated due to Middle East respiratory syndrome. Epidemiol Health. 2016:38:e2016048, https://doi.org/10.4178/epih.e2016048.

34. Wang $X$. Demand for face masks surges in China amid outbreak. Chinadaily. com.cn, 2020-01-21. https://www.chinadaily.com.cn/a/202001/21/WS5e2 69c47a31012821727289e.html.

35. Bao Y, Sun Y, Meng S, Shi J, Lu L. 2019-nCoV epidemic: address mental health care to empower society. Lancet. 2020;395(10224):e37-8. https://doi. org/10.1016/S0140-6736(20)30309-3.

36. Ahmed MZ, Ahmed O, Aibao Z, Hanbin S, Siyu L, Ahmad A. Epidemic of COVID-19 in China and associated psychological problems. Asian J Psychiatr. 2020:51:102092. https://doi.org/10.1016/j.ajp.2020.102092.

37. Qiu JY, Shen B, Zhao M, Wang Z, Xie B, Xu YF. A nationwide survey of psychological distress among Chinese people in the COVID-19 epidemic: implications and policy recommendations. Gen Psychiat. 2020;33(2)

38. Ministry of Emergency.The latest cases of COVID-19 patients. National Health Commission of the People's Republic of China; 2020. http:// www.nhc.gov.cn/xcs/yqtb/202002/bfebf84fb88248e4a4eba61295e5882b. shtml.

39. Mak IW, Chu CM, Pan PC, Yiu MG, Chan VL. Long-term psychiatric morbidities among SARS survivors. Gen Hosp Psychiatry. 2009;31(4):318-26. https://doi.org/10.1016/j.genhosppsych.2009.03.001.

40. World Health Organization.Advice on the use of masks the community, during home care and in health care settings in the context of the novel coronavirus (2019-nCoV) outbreak. Geneva: WHO; 2020. https://www.who. 
int/docs/default-source/documents/advice-on-the-use-of-masks-2019-ncov. pdf.

41. Jecker NS, Wightman AG, Diekema DS. Vaccine ethics: an ethical framework for global distribution of COVID-19 vaccines. J Med Ethics. 2021. https://doi. org/10.1136/medethics-2020-107036.

42. Dar KA, Iqbal N, Mushtaq A. Intolerance of uncertainty, depression, and anxiety: examining the indirect and moderating effects of worry. Asian J Psychiatr. 2017;29:129-33. https://doi.org/10.1016/j.ajp.2017. 04.017.

43. Ziaian T, de Anstiss H, Antoniou G, Baghurst P, Sawyer M. Resilience and its association with depression, emotional and Behavioural problems, and mental health service utilisation among refugee adolescents living in South Australia. Int J Popul Res. 2012;2012:1-9. https://doi.org/10.1155/2012/4 85956.

44. Scali J, Gandubert C, Ritchie K, Soulier M, Ancelin ML, Chaudieu I. Measuring resilience in adult women using the 10-items Connor-Davidson Resilience Scale (CD-RISC). Role of trauma exposure and anxiety disorders. PLoS One. 2012; (6):e39879

45. Fu C, Leoutsakos JM, Underwood C. An examination of resilience crossculturally in child and adolescent survivors of the 2008 China earthquake using the Connor-Davidson resilience scale (CD-RISC). J Affect Disord. 2014; 155:149-53. https://doi.org/10.1016/j.jad.2013.10.041.

46. Charney DS. Psychobiological mechanisms of resilience and vulnerability: implications for successful adaptation to extreme stress. Am J Psychiatry. 2004;161 (2):195-216. https://doi.org/10.1176/appi.ajp.161.2.195.

47. Gallagher S, Doherty DT. Searching for health information online: characteristics of online health seekers. J Evid Based Med. 2009;2(2):99-106. https://doi.org/10.1111/j.1756-5391.2009.01021.x.

48. Wang J, Cooke FL, Huang W. How resilient is the (future) workforce in China? A study of the banking sector and implications for human resource development. Asia Pac J Hum Resour. 2014;52(2):132-54. https://doi.org/1 0.1111/1744-7941.12026.

49. Ahmed AS. Post-traumatic stress disorder, resilience and vulnerability. Adv Psychiatr Treat. 2018;13(5):369-75. https://doi.org/10.1192/apt.bp.106.003236.

50. Gerino E, Rolle L, Sechi C, Brustia P. Loneliness, resilience, mental health, and quality of life in old age: a structural equation model. Front Psychol. 2017;8: 2003. https://doi.org/10.3389/fpsyg.2017.02003.

51. Lee D, Yu ES, Kim NH. Resilience as a mediator in the relationship between posttraumatic stress and posttraumatic growth among adult accident or crime victims: the moderated mediating effect of childhood trauma. Eur J Psychotraumatol. 2020;11(1):1704563. https://doi.org/10.1080/20008198.201 9.1704563.

52. Horn SR, Charney DS, Feder A. Understanding resilience: New approaches for preventing and treating PTSD. Exp Neurol. 2016;284(Pt B):119-32.

53. Roy MJ. The assets-based approach: furthering a neoliberal agenda or rediscovering the old public health? A critical examination of practitioner discourses. Crit Public Health. 2017;27(4):455-64. https://doi.org/10.1080/ 09581596.2016 .1249826$.

54. Tracey S, O'Sullivan TL, Lane DE, Guy E, Courtemanche J. Promoting Resilience Using an Asset-Based Approach to Business Continuity Planning. SAGE Open. 2017;7(2). https://doi.org/10.1177/2158244017706712.

\section{Publisher's Note}

Springer Nature remains neutral with regard to jurisdictional claims in published maps and institutional affiliations.

Ready to submit your research? Choose BMC and benefit from:

- fast, convenient online submission

- thorough peer review by experienced researchers in your field

- rapid publication on acceptance

- support for research data, including large and complex data types

- gold Open Access which fosters wider collaboration and increased citations

- maximum visibility for your research: over $100 \mathrm{M}$ website views per year

At BMC, research is always in progress.

Learn more biomedcentral.com/submissions 